\title{
Post-irradiation effects on Nylon-fibers reinforced concretes
}

\begin{abstract}
Gonzalo Martínez-Barrera, ${ }^{1,2}$ * Carmina Menchaca-Campos, ${ }^{3}$ Enrique ViguerasSantiago, ${ }^{1,2}$ Witold Brostow ${ }^{2}$

${ }^{1 *}$ Laboratorio de Investigación y Desarrollo de Materiales Avanzados (LIDMA), Facultad de Química, Universidad Autónoma del Estado de México, Km.12 de la carretera Toluca-Atlacomulco, San Cayetano 50200, Mexico; fax +52-722- 2175109; email: gonzomartinez02@yahoo.com.mx.

${ }^{2}$ Laboratory of Advanced Polymers \& Optimized Materials (LAPOM), Department of Materials Science and Engineering and Center for Advanced Research and Technology (CART), University of North Texas, 1150 Union Circle \# 305310, Denton, TX 76203-5017, USA; email: wbrostow@yahoo.com; http://www.unt.edu/LAPOM/

${ }^{3}$ Centro de Investigación en Ingeniería y Ciencias Aplicadas (CIICAp), Universidad Autónoma del Estado de Morelos, Cuernavaca, Morelos 62210, Mexico; ecmenchaca@yahoo.com.mx
\end{abstract}

(Received: 14 May, 2009; published: 06 April, 2010)

\begin{abstract}
Fiber-reinforced concretes (FRCs) have a wider application range than ordinary concretes. Properties of FRCs necessarily depend on the characteristics of the aggregates used. We have studied first effects of gamma radiation on mechanical properties of hydraulic concretes containing Portland cement, silica sand, marble, water and Nylon fibers. Compressive strength and dynamic elasticity modulus are of particular importance. In the second stage we have analyzed the changes in these mechanical properties after storage of our concretes for three years. The long storage results in a $97 \%$ of increment in the compressive strength and simultaneous lowering by $35 \%$ of the dynamic elastic modulus. We find a larger influence of the Nylon fibers than those of silica sand and marble on mechanical properties of the concretes.
\end{abstract}

\section{Introduction}

The commercial success of polyamides is due to their outstanding properties and economical advantages. Most of them - including Nylon - are used in fiber production. Nylon fibers have been used since early 1980s for secondary temperature-shrinkage reinforcement in shotcrete and concrete [1,2].

Concrete is one of the oldest materials used by mankind, a composite par excellence [3]. A large variety of methods of improving it have been developed [4 - 6]. Several improvements can occur when adding fibers into the Portland cement concrete (PCC): a) higher impact resistance by lowering the extent of stretching at large strains, thus preventing failure of the matrix at relatively low loads; b) higher compressive, tensile and abrasive strength; c) service in adverse environments (wind, moisture, etc.); d) lower weight and costs; e) reduction in craze cracking due to higher compressive stresses; f) creation of a 3-D network of reinforcement with 
superior fiber/mix bonding; and g) reduction of bleeding and thus the number of bleed channels, resulting in less water migration to the concrete surface [7 - 12].

Fibers known as monofilaments and fibrillated (from 13 to $38 \mathrm{~mm}$ long), are typically added into the concrete from 0.6 to $0.9 \mathrm{~kg} / \mathrm{m}^{3}$. On occasions more than $1.8 \mathrm{~kg} / \mathrm{m}^{3}$ dosages are used: a) as a superior secondary reinforcement for precast concrete or shotcrete; and b) in seismic applications, industrial slabs, and ultra-thin white topping. The fiber characteristics as content or length have a higher influence on the concrete features. For example, Nylon monofilaments $19 \mathrm{~mm}$ long are more effective for the shrinkage crack reduction in lean mortars and concrete than in rich-cement mortar. Moreover, when adding 0.1 vol. \% of Nylon fibers, higher stress levels can be applied $[10,11]$. Other important characteristics of the Nylon fibers are high crystallinity, high mechanical properties, outstanding wet strength retention, low tissue reaction and chemical resistance [13]. We need also to take into account that irradiation can affect in a positive way properties of concretes [14, 15].

Macro-fibers are distinguished by their typically longer length (with $38 \mathrm{~mm}$ considered a minimum) and wider fibril cross-sections. They are added at higher dosage rates to the concrete, typically from 3 to $9 \mathrm{~kg} / \mathrm{m}^{3}$. The addition limits the damaging effects of a seismic event or concussive energy. In the case of Nylon-6 fibers, improvement of the postcrack resistance is obtained when adding for instance $4.75 \mathrm{~kg} / \mathrm{m}^{3}$ of them to concrete. Moreover, the fibers are not affected by the alkaline environment and they demonstrate their long-term durability in the concrete.

The initial bonds between the fibers and the concrete can be attributed to physical adhesion and static friction caused by the surface finish of the fibers. Chemical bonding (sometimes referred to as elastic bonding) between the fibers and the matrix is not strong in comparison to frictional resistance along the debonded segment against pull-out. In general, friction plays an important role with increasing fiber size in confining stress. Most fiber deformation processes lead to local mechanical interactions between fibers and matrix.

The techniques employed to modify interfacial bonds between polymeric fibers and cementitious matrices include fibrillation and twisting deformation of the fibers. The fibrillation increases the surface contact area and enhances mechanical anchoring to the matrix - as well as improves the fibers modulus. Both techniques are particularly suitable for polymeric fibers due to their low strength and large strain capacity. In the case on Nylon fibers, the pull-out process can be significantly altered by mechanically crimping of the fibers; moreover, the mechanical bond is so strong that pull-out of the fiber is limited by the strength of the Nylon fibers [16]. Eventual failure of the fibers as well as of concrete is brittle; concrete disintegrates into pieces in a rather sudden way, while the fibers largely still preserve their original size [8]. We recall that brittleness $B$ is inversely proportional to the elongation at break $[17,18]$.

Nylon fibers substantially improve the impact resistance of concrete due to stretching and pull-out of the fibers - phenomena that occur at relatively low loads and result in large strains at failure. Nevertheless, the added fibers have only little effect on tensile or bending strength. Thus, it would be advantageous if concrete could be designed to support an increasing load after the cracking of the matrix. This can be achieved by improving the stress transfer from the matrix to the fibers after matrix failure by modifying the fiber surface [7]. 
In general, the dynamic elastic modulus $E_{d}$ serves well for hard as well as fragile materials. $E_{d}$ can determine by measuring the pulse velocity along the composite using electrical transducers located on the opposite sides of the cylindrical specimens of concrete. The energy supplied by the ultrasound depends of how compact the composite is - including the void presence and sizes. $E_{d}$ can be calculated as:

$E_{d}=u^{2} w(1+v)(1-2 v) /(1-v)$

here $u$ is the pulse velocity; $w$ is the weight of the concrete specimen and $v$ is the Poisson ratio.

The dynamic elastic modulus depends on the component properties of the aggregates and their relationship with the cement. It is well known that the pulse velocity is faster in coarse aggregate than in the cement paste. Others methods of non-destructive testing of concretes have been developed, including a method of Berthelot e.a. using wave attenuation [19].

It is well known that gamma radiation induces alterations of the polymer structure via three main processes: scission, crosslinking and grafting of chains, each one depends on the applied dose. Thus, irradiation has been used to improve tribological properties of polymers by Brocka and her colleagues [20]. It has been claimed that chain scission - either in the amorphous region or inside the crystals - begins with formation of free radicals [21]. An advantage of high-energy irradiation is the capability to work in the solid state, and to reduce the cost and time; this in contrast to other procedures in use such as chemical attack or thermal treatment $[22,23]$.

In the case of Nylon fibers, modifications in the chemical structure and control of the recrystallization process by using gamma radiation are important areas for developing consumer products for a wide range of applications. During irradiation of Nylon fibers, first chain scission (caused by the Compton Effect and subsequent rearrangement of radical cations formed in the process), relaxation and breaking of 'cages' confining certain sequences of chain segments occured. This occurs mainly in the amorphous zones of the fibers [24]. A second stage involves decrease of microcrystal sizes and chain reorientations, with activation energy smaller than in the first stage. Finally, in the third stage, given the supplied energy, the chemical bonds within the crystallites are breaking, including $\mathrm{C}-\mathrm{N}$ bonds [25]. However, this is not enough to counteract an ongoing scission process; oligomer re-polymerization is taking place, creating larger crystalline clusters; consequently, a permanent damage occurs [25, 26]. The mechanism described affects the fusion temperature, because this property is associated with the number of carbons in the chain, consequently with the mean molecular weight. Variations observed in the temperatures of fusion correspond to crosslinking or chain scission processes - as well as to the mean crystal size and the heat of fusion [27]. In the low radiation dose zone (up to $50 \mathrm{kGy}$ ), temperature increases and the mean crystal size increases also. At higher doses the opposite behavior is found.

For Nylon 6,12 fibers irradiated at 15 and $50 \mathrm{kGy}$, a lamellar structure (elongated crystallites) is formed - while cylindrical shapes are seen for higher doses up to 300 kGy. Moreover, a gradual color change from white to a yellow-creamy is seen, most notable at $300 \mathrm{kGy}$. As we know, a color change is one of the main manifestations of free radicals formation and chemical degradation when the applied radiation dose is increasing [25]. Sometimes Nylon 6,12 fiber degradation begins at a low dose (5 - 10 
kGy) while for higher doses (100 kGy) scrap particles emerge from the fibers - a consequence of the formation of oligomers created by scissions of the chains [28].

Nylon 6,12 irradiated fibers have a preferred crystal orientation according to Raman scattering studies. This depends on vertical or horizontal orientation of the sample with respect to the laser beam direction [19]. Nevertheless, some properties are different when Nylon fibers are irradiated in argon atmosphere: the fibers do not show changes in their crystalline structure, there is a homogeneous mean crystal size, and an increase in the number and depth of the surface scratches [23].

Another important aspect that requires attention is aging of the fibers after irradiation. This pertains not only to the Nylon fibers but to $\gamma$-irradiated polymers in general [29, 30]. Long term effects on Nylon irradiated fibers show changes in the shape and the crystallinity degree. The crystallite size increases (from three to five times) and more cracks are formed on the surface with the storage time. The surface cracks have a preferential orientation and the scratches increase along the fiber direction [26].

When adding Nylon irradiated fibers to the Portland cement concrete (PCC), improvements in mechanical properties have been found. Periodical behavior, as noted in our earlier papers, namely "decrement-increment-decrement-etc" in the values of compressive strength of concrete, can be related to mechanical properties and morphology of the irradiated Nylon fibers [28, 31].

Concretes with irradiated Nylon-fibers show a maximum value for compressive strength, when adding fibers irradiated at $50 \mathrm{kGy}$, a lamellar structure is seen in scanning electron microscopy (SEM). Moreover, at the same irradiated dose of 50 kGy, tensile testing of Nylon fibers shows maximum values of the tensile stress and tensile strain at yield point [31]. The highest compressive values for concrete are obtained for the highest strain values of the fiber. Thus, a mechanism of load transfer between the concrete and fibers under loading is seen. Moreover, a reinforced concrete is created with high elastic modulus and high deformability - a feature not typical for hydraulic concrete [26, 28]. These results can be related to those obtained by Raman spectroscopy [13] where $50 \mathrm{kGy}$ seems to be the dose at which Nylon 6,12 fibers change their molecular response to gamma radiation. Peaks intensities become more stable and higher doses diminish the quality of the fibers. Furthermore, $50 \mathrm{kGy}$ seems to be the dose at which the reaction mechanism changes from crosslinking to chain scission [32].

The compressive strength values for the concrete go down when adding fibers irradiated between 50 and $100 \mathrm{kGy}$. At these doses, the fiber elongation decreases and each fiber become harder [31]. At $100 \mathrm{kGy}$, the fiber surface morphology shows the formation of small spherical particles and scrap particles (less than $1 \mu \mathrm{m}$ in length) resulting from the chain scissions; these particles take the role of fillers in the composite and interact more with the cement matrix rather than with the Nylon fibers $[26,28]$. Moreover, tensile studies reveal changes in flexibility of the fibers - as reflected in changes in the tensile modulus $[8,26]$.

The compressive strength behavior of concrete depends mainly on two parameters: fiber contents and radiation dose. For concrete containing $1.5 \mathrm{vol}$. \% of irradiated Nylon fibers the highest compressive values are obtained for $10 \mathrm{kGy}$, different from 50 kGy necessary for 2.0 and 2.5 vol. \% of irradiated fibers [31].

Some other features reported concerning fiber reinforced concretes are: a) The contact points resist the load by inclined forces, oriented at some angle relatively to 
the longitudinal axis of the fibers; b) the splitting cracks follow the reinforcing fibers, and the bond transfer drops rapidly unless reinforcement is provided to restrain the opening of the splitting crack; and c) concrete will split parallel to the fibers and the resulting crack will propagate out to the surface [8]. Gamma radiation produces further effects: d) ionizing energy generates more contact points on the fiber surfaces and in consequence a larger contact area between the fibers and the concrete phase appears [33]; and e) an increment in the number and depth of scratches - that also enhances interactions between fibers and concrete components [23]. Kopczynska and Ehrenstein discuss how interfaces largely determine properties of multiphase materials [34].

In the present work we have studied gamma post-irradiation effects on the compressive strength and dynamic elastic modulus properties of Portland cement concrete containing Nylon fibers - after storage for three years

\section{Results and discussion}

\section{Compressive strength}

The compressive strength values for not stored and non-irradiated (NS-NI) and nonstored and irradiated (NS-I) concretes are shown in Figure 1. In general, for each particular radiation dose the phenomenon is the same: the compressive strength increases when the nylon fibers content increases. The values for NS-NI concretes vary from 19.2 to $21.9 \mathrm{MPa}$ and for NS-I concretes from 19.7 to $27.5 \mathrm{MPa}$; this means a maximum improvement of $25 \%$ with respect to non-irradiated concrete. In general, the values increase when applying doses up to $100 \mathrm{kGy}$; for the higher dose of $150 \mathrm{kGy}$ the values go down significantly.

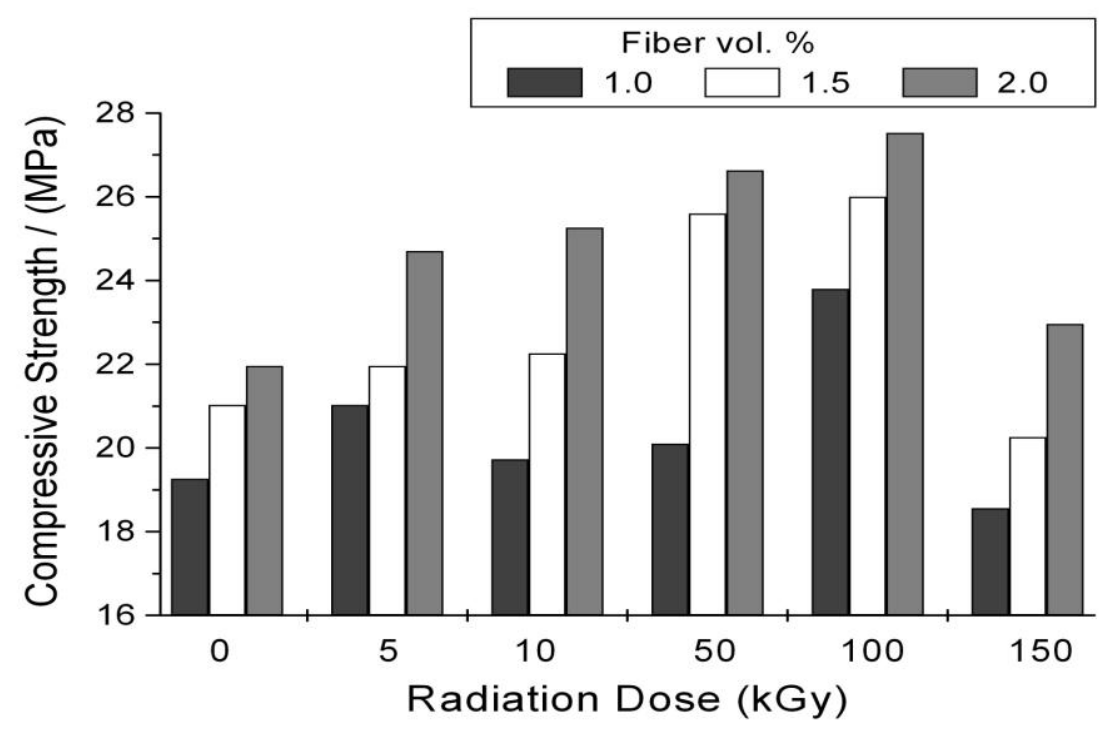

Fig. 1. Compressive strength of non-storage Nylon-fiber reinforced concrete, at different radiation dose.

Following the radiation dose as parameter, for each fiber content different behavior is seen. For 1.0 vol. \% of Nylon fibers, four stages are observed: I) the compressive strength increases from zero-irradiation to $5 \mathrm{kGy}, \mathrm{II})$ it decreases for $10 \mathrm{kGy}$, III) 
increases again up to 100 kGy, and finally IV) decreases for 150 kGy. In the cases of 1.5 and 2.0 vol. \% of fibers, there are only two stages: I) the values are increasing from non-irradiation to $100 \mathrm{kGy}$, and then II) they decrease for $150 \mathrm{kGy}$. Thus, it is easier to predict the behavior for 1.5 and 2.0 vol. \% of fibers.

When comparing the compressive strength values of NS-NI concretes with those concretes elaborated with the same nylon fibers and silica sand but using gravel as aggregate (instead of marble as in the present study), we find lower values for the present concretes: 26 and $27.5 \mathrm{MPa}$ for 1.5 and 2.0 vol. \% of nylon fibers, instead of 34.2 and $37.5 \mathrm{MPa}$, respectively, for concretes with gravel [31]. We find that the use of gravel in the concretes increases the compressive strength more than marble does.

After storage, notable changes are observed in the concretes - as presented in Figure 2. In general, the concretes stored for 3 years (3YS-NI and 3YS-I) have higher compressive strength values than fresh concretes (NS-NI and NS-I). When comparing both kinds of concretes (stored and otherwise) we can appreciate improvements in the compressive strength. A maximum improvement of $52.6 \%$ is obtained for the 3YS-NI concretes with respect to NS-NI concretes. In the other pair of kinds of materials, the 3YS-I concrete shows a maximum improvement of $97.3 \%$ with respect to NS-I concrete.

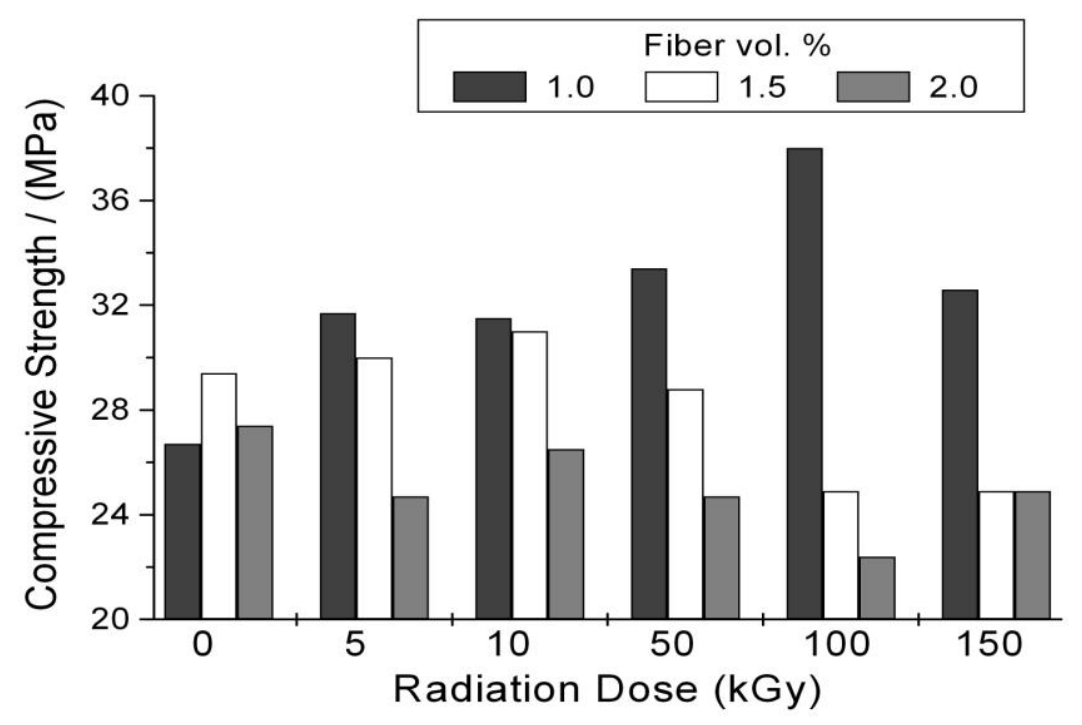

Fig. 2. Compressive strength of stored Nylon-fiber reinforced concretes at several irradiation doses.

Two phenomena are observed in Figure 2. The first one concerns 3YS-NI concretes, where the values show a maximum for concrete with $1.5 \mathrm{vol}$. \% of Nylon fibers; the values vary from 26.7 to $29.4 \mathrm{MPa}$, a variation of $10.1 \%$. The second phenomenon worth noting is the behavior of the 3YS-I concretes: for each radiation dose, the compressive strength decreases when the Nylon fibers contents increases. Thus, the behavior is totally contrary to that found for NS-NI and NS-I concretes.

Analyzing the compressive strength according to the fibers content, we find the following: a) for $1.0 \mathrm{vol}$. \% of Nylon fibers, the compressive strength values increase 
along with an increase in the radiation dose up to $100 \mathrm{kGy}$ while at higher doses the values decrease; b) for 1.5 and 2.0 vol. \% of fibers, the values increase up to certain dose and then decrease for higher radiation doses, the maxima appearing at 10 and $100 \mathrm{kGy}$, for 1.5 and 2.0 vol. \%, respectively.

A different presentation of the results is provided in Figure 3. Now, the compressive strength is shown as a function of the Nylon fiber content. Notable are the differences between non-stored and stored concretes. All results for irradiated concretes after 3 year storage (3YS-I) are higher than for non-stored irradiated materials (NS-I). Indeed, for 3YS-I concrete with 1.0 vol. \% of Nylon fibers the improvement amounts to $97.3 \%$; the respective number is $47.7 \%$ for $3 Y S-I$ concrete with $1.5 \%$ fibers, and finally $20.6 \%$ for 3 YS-I concrete with $2.0 \%$ fibers.

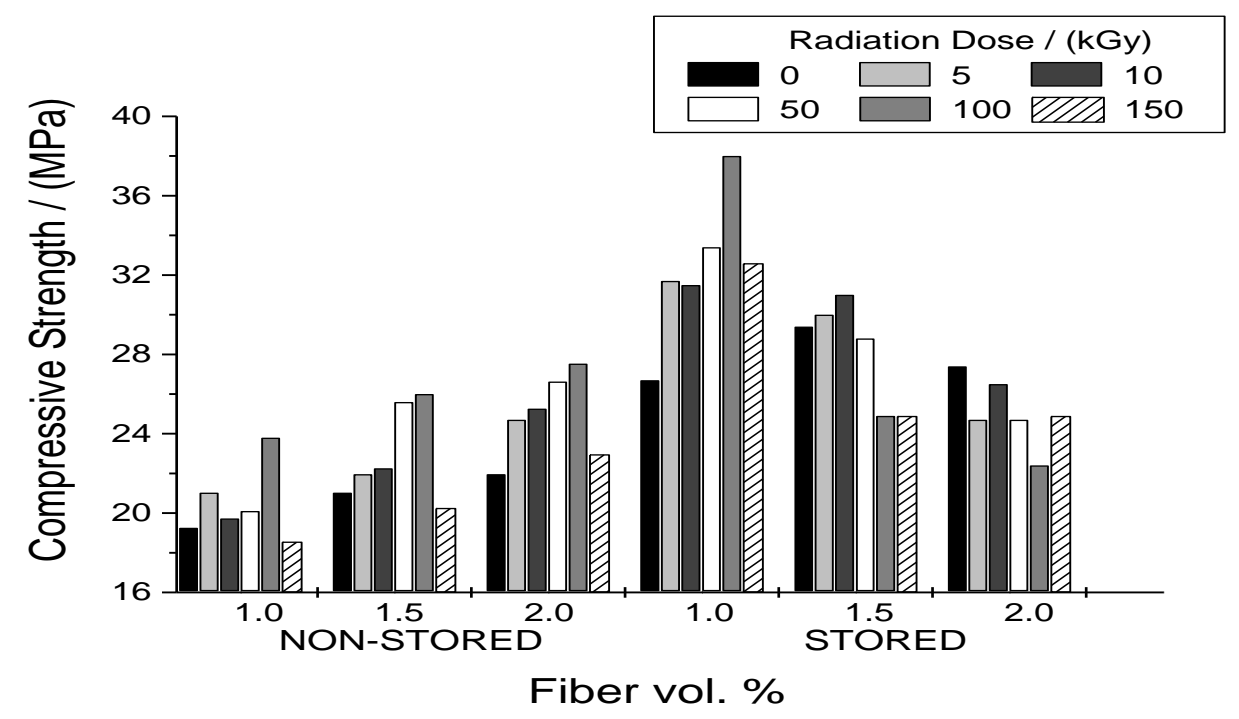

Fig. 3. Compressive strength of non-stored and stored concretes (NS and 3YS) at several irradiation doses.

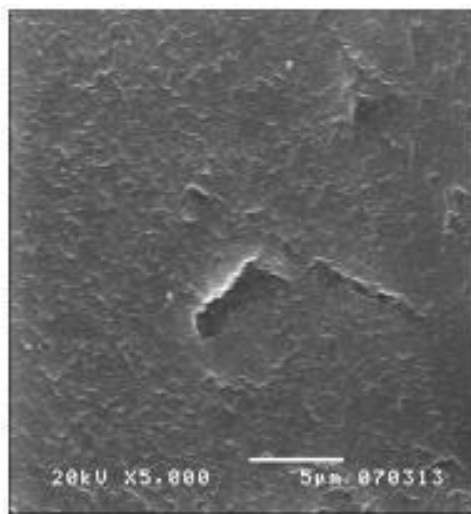

a)

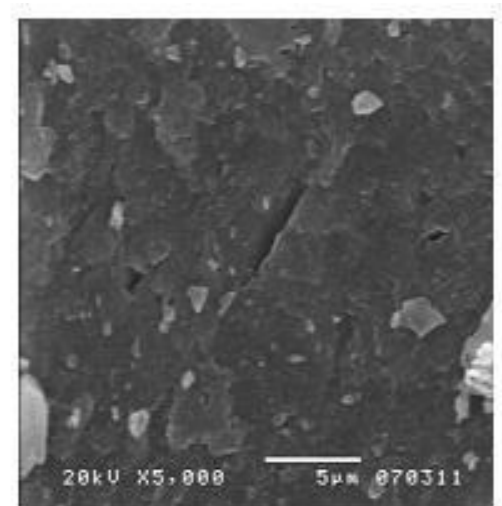

b)

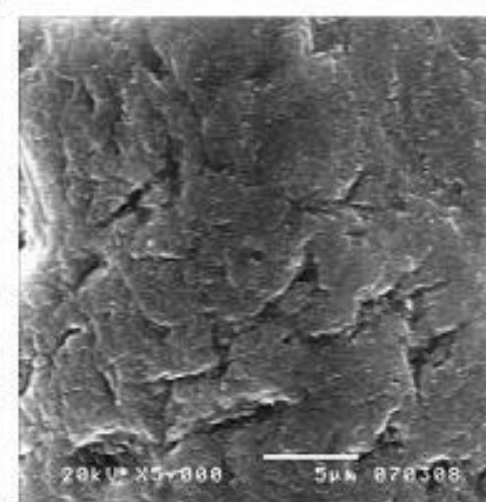

c)

Fig. 4. SEM Micrographs of silica sand: a) non-irradiated, b) irradiated at $50 \mathrm{kGy}$, and c) irradiated at $150 \mathrm{kGy}$. 
For non-stored concretes the compressive strength values are increasing when the Nylon fiber content increases. For stored concretes the behavior is completely opposite. These facts suggest that the beneficial results of aging in storage are hampered by increasing the Nylon fibers concentration above $1 \%$.

The compressive strength performances after three years of storage can be related to morphological changes of the mineral aggregates and Nylon fibers after gamma irradiation. Surface modifications of silica sand seen in SEM are shown in Figure 4. Evident is deterioration of silica sand surfaces with increasing irradiation. For nonirradiated silica sand an homogeneous surface is seen, with a few cracks $\approx 5 \mu \mathrm{m}$ long (Figure 4a); when increasing the radiation dose, several particles smaller than 5 $\mu \mathrm{m}$ in average size appear (Figure 4b); and finally for the high dose of $150 \mathrm{kGy}$ deteriorated surface with several cracks (Figure 4c) is seen. We can relate the lower compressive strength values at higher dosages with cracks propagating on surfaces of silica sand particles.

\section{Dynamic elastic modulus}

Behavior of the dynamic elastic modulus $E_{d}$ is different from that of the compressive strength. In Figure 5 we show $E_{d}$ values for non-stored concretes: non-irradiated and irradiated (NS-NI and NS-I). For NS-NI concretes the modulus decreases when adding more Nylon fibers. In the case of NS-I concretes a periodic behavior is seen, involving three well-defined stages: I) the values decrease from 5 to $10 \mathrm{kGy}$; II) they increase up to $100 \mathrm{kGy}$, and finally III) they decrease at $150 \mathrm{kGy}$.

Small differences in the $E_{d}$ values are found for all concretes, varying from 23.6 to $25.1 \mathrm{GPa}$, the maximum difference of $6.3 \%$ between them. In this sense we can talk about a "quasi-constant" value of $E_{d}$ for non-stored concretes. The values for NS-NI concretes have a difference of $2.0 \%$ between them.

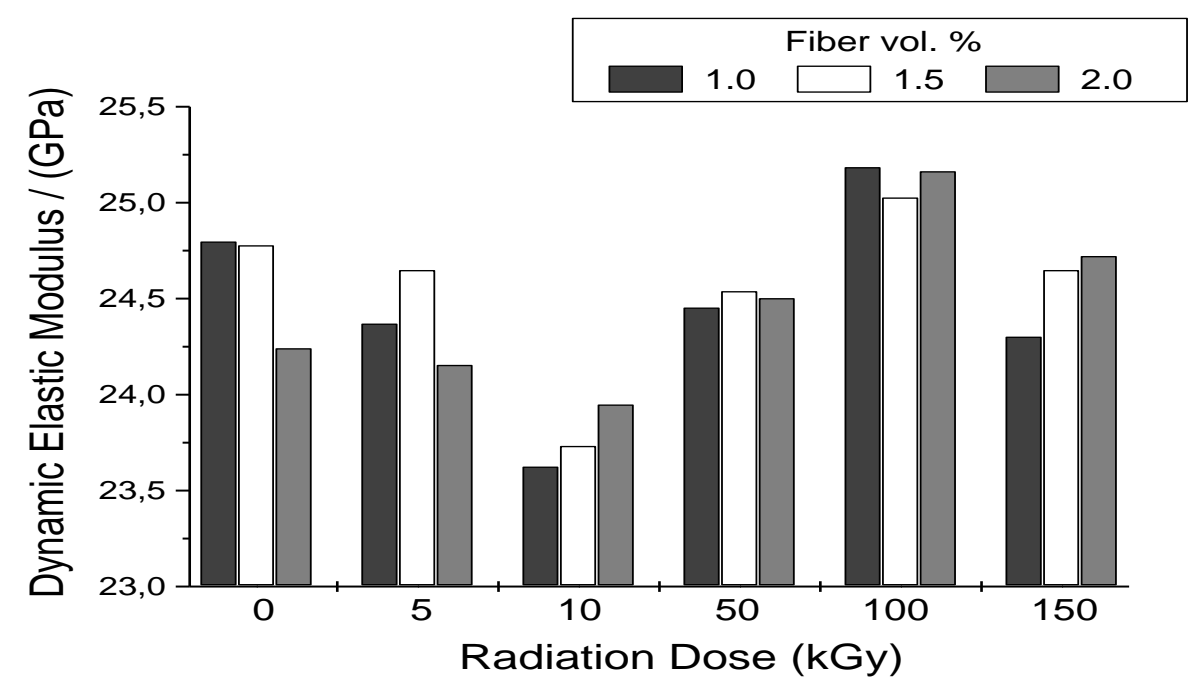

Fig. 5. Dynamic elastic modulus of non-stored Nylon-fiber reinforced concretes at several radiation doses.

We now turn to stored concretes, non-irradiated and irradiated (3YS-NI and 3YS-I). $E_{d}$ values are displayed in Figure 6 . We see that all concretes have lower values with 
respect to non-stored ones; compare Figure 5. Indeed, 3YS-NI concretes show a decrease of $30 \%$ with respect to NS-NI concretes. For 3YS-I concretes with respect to NS-I concretes the decrease is larger and amounts to $36 \%$.

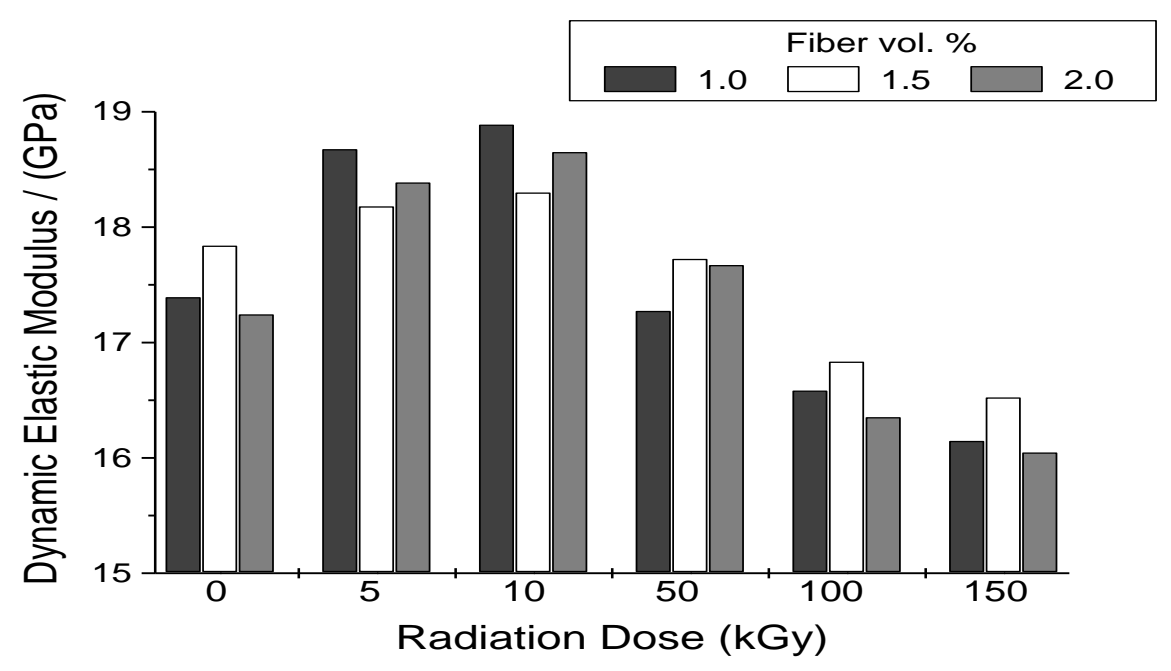

Fig. 6. Dynamic elastic modulus of storage Nylon-fiber reinforced concrete, at different radiation doses.

If we follow in Figure 6 the behavior of $E_{d}$ values according to the fiber content, we find the same behavior for the three different Nylon fiber contents, namely the modulus shows two well-defined stages: I) an increase from zero to $10 \mathrm{kGy}$, and II) a decrease for higher doses, up to $150 \mathrm{kGy}$.

We now consider an effect of the fiber contents more in detail; see Figure 7. It is evident that for non-stored concretes the variations of the values of the dynamic elastic modulus are quite small. For the case of stored concretes, the pattern for each Nylon fiber content is the same: an increase up to $10 \mathrm{kGy}$, and then a decrease for higher doses. The overall values are lower than those for non-stored concretes.

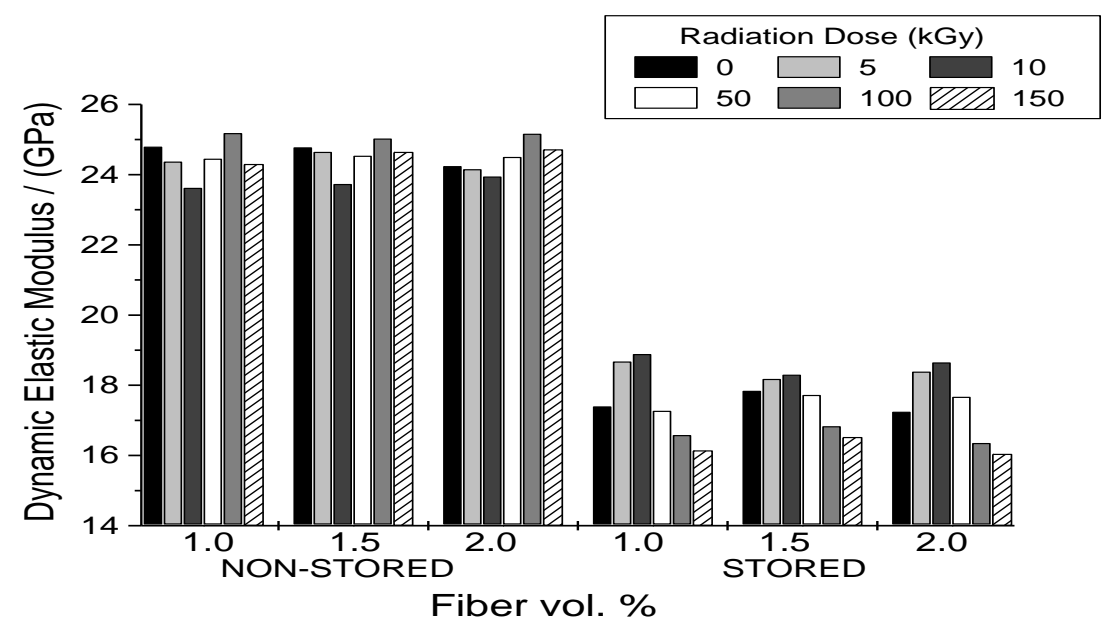


Fig. 7. Dynamic elastic modulus of non-stored and stored concretes (NS and 3YS) at different radiation doses.

As noted previously, mechanical performance can be related to morphological changes on the surfaces. The $E_{d}$ values for stored concretes (3YS-NI and 3YS-I) are lower than for non-stored ones. The former concretes are more ductile - pertinent in the case of seismic events. We related the observed ductility to the polymeric component in our composites that is to nylon fibers. We see in Figure 8 that the marble morphology exhibits similar behavior to the silica sand. That is, for nonirradiated marble, several particles are seen (Figure 8a); after increasing the gamma radiation dose to $50 \mathrm{kGy}$, more particles with larger sizes appear (Figure 8b). For the high dose of $150 \mathrm{kGy}$, the particle size is still larger due to degradation of the marble (Figure 8c).

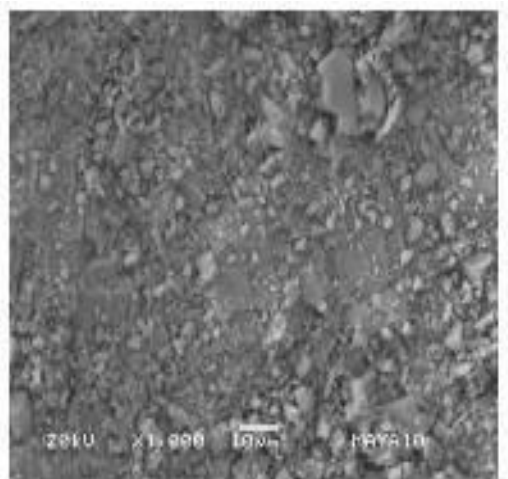

a)

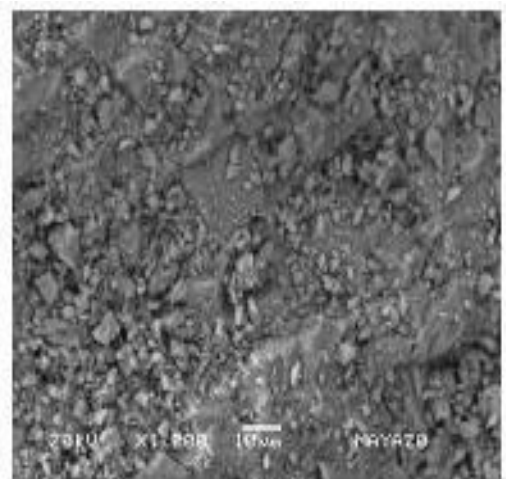

b)

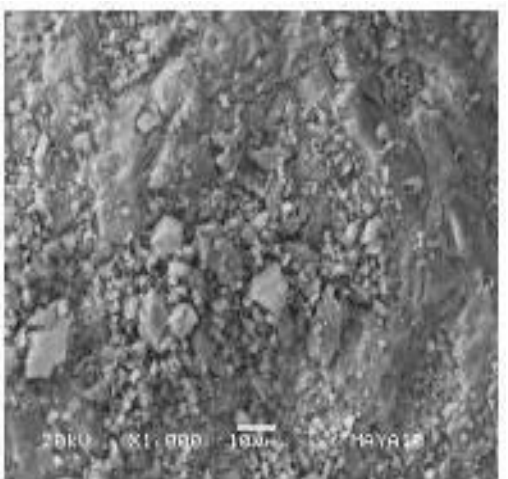

c)

Fig. 8. SEM Micrographs of marble: a) non-irradiated, b) irradiated at $50 \mathrm{kGy}$, and c) irradiated at $150 \mathrm{kGy}$.

We recall that in irradiated Nylon fibers previously studied by us the morphological changes depend of the applied dose. Degradation begins at low doses (5 to $10 \mathrm{kGy}$ ); for higher doses lamellar structures (elongated crystallites) are formed (up to 50 kGy); for dose of 100 kGy or more, cylindrical shapes are seen and scrap particles emerge from the fibers - a consequence of the formation of oligomers created by scissions of the chains $[13,25]$. Moreover, post-irradiating effects on Nylon fibers show two important effects; both the crystallite size and the surface damage increases with storage time. These effects can be attributed to irradiation causing chain scission; this in turn causes crystal reorganization [26].

We can relate the compressive strength and the elastic modulus to morphological changes in silica sand, marble and Nylon fibers. Degradation is observed for all these three components, but their combination generates after storage concretes with higher compressive strength and lower elastic modulus. In particular, when the radiation dose increases more cracks on silica sand and more disintegrated particles on marble are seen. In the case of Nylon fibers more scrap particles are present. That is, the ionizing energy generates more contact surfaces on the three components and thus larger contact areas between them and the hydrated cement phase.

Slow disintegration of silica sand and marble as well as crystallite formation on Nylon fibers generates a material with higher compressive strength values. After storage, 
growth of the crystal sizes of Nylon fibers and large degradation of silica sand and marble have as a consequence increase of the compressive strength. A strong interaction between the ceramic matrix and the Nylon fibers is seen. Moreover, the occurrence of continuous chemical reactions over three years results in: a) chain scissions (taking place in the amorphous zone), followed by chain reorientations, leading to larger crystalline clusters in the Nylon fibers, and b) growth of cracks on silica sand. We find a larger influence of the Nylon fibers (polymeric material) on the strain performance than those of silica sand and marble (ceramic materials). Lowering of the elastic modulus values is seen. In other words: Nylon fibers interact more with disintegrated marble particles, hence more contact points and a more ductile material.

\section{Conclusions}

Improvements caused by gamma radiation of the compressive strength and dynamic elastic modulus of Nylon reinforced concrete depend on content of Nylon fibers and the dose applied to the concrete. Changes in these mechanical parameters during three years of storage time are quite large. These changes can be related to morphological modifications of the main components: Nylon fibers, silica sand and marble.

\section{Experimental part}

\section{Specimen preparation}

Before preparing the concrete specimens, one set of Nylon 6,12 crystalline fibers (E.I. du Pont de Nemours, Wilmington, Delaware) whose diameters varies from 30 to $40 \mu \mathrm{m}$ were cut to the approximate length of $5 \mathrm{~mm}$. The fibers so obtained were mixed into the concrete (at $1.0,1.5$ or $2.0 \%$ in volume). The concrete was made from Portland cement (Cruz Azul ${ }^{\mathrm{TM}}$, Monterrey NL, Mexico) and silica sand and marble, from a local company (GOSA ${ }^{\mathrm{TM}}$, Atizapan, Mexico).

The proportions of components in the concrete were 1/2.75 for cement/aggregates, and the water/cement ratio of 0.485 according to the ASTM C-305 standard. The average sizes of silica sand particles were from 150 to $355 \mu \mathrm{m}$ (mesh 100 and 45, respectively), and for the marble of $1.4 \mathrm{~mm}$ (mesh 14).

18 different lots were made on different days, each containing six samples. That is, for each Nylon fiber content, 36 concrete specimens were prepared. After mixing, the concrete cylindrical specimens (2" diameter and 4" long) were placed in a controlled temperature room at $23.0 \pm 3.0^{\circ} \mathrm{C}$, with the surface exposed to moisture in air and no less than $50 \%$ humidity according to the ASTM C-511 standard.

\section{Irradiation procedure}

The concrete specimens were exposed to varying gamma radiation doses $(5,10,50$, 100 and $150 \mathrm{kGy}$ ) in air at room temperature. For a complete analysis, silica sand and marble were irradiated in the same way. The dose rate $3.5 \mathrm{kGy} / \mathrm{hr}$ was applied by using a 651 PT Gammabeam Irradiator with a ${ }^{60}$ Co source, manufactured by the Atomic Energy of Canada Ltd. (now NORDION, Chalk River, Ontario), and located at the Institute of Nuclear Sciences of the National Autonomous University of Mexico.

One half of the total concrete specimens were in storage for a period of three years in a controlled temperature room at $23.0 \pm 3.0{ }^{\circ} \mathrm{C}$, with the surface exposed to 
moisture in air and no less than $50 \%$ humidity according to the ASTM C-511 standard.

We have thus created four kinds of concrete specimens: 1) fresh and non-irradiated (NS-NI); 2) not stored and irradiated (NS-I) tested three years ago; 3) stored and non-irradiated (3YS-NI), and 4) stored for 3 years and irradiated (3YS-I).

\section{Mechanical Tests}

The compressive strength of the concrete cylindrical specimens was measured with a hammer model 58-C1081/N apparatus (Controls ${ }^{\mathrm{TM}}$, Cernusco, Italy). The equipment quantifies the number of rebounds supported in a specific area of each specimen. The testing allowed tolerance for the specimens was 28 days \pm 12 hours.

Dynamic elastic modulus $E_{d}$ of the concrete cylindrical specimens was determined with an ultrasonic testing equipment for building materials: Ultrasonic Pulse Velocity Tester model 58-E0048 (Controls ${ }^{\mathrm{TM}}$, Cernusco, Italy), with an ultrasonic resolution of $0.1 \mathrm{~ms}$. The equipment measures the ultrasonic propagation through the concrete specimens; see Eq. (1) above.

\section{Morphological characterization}

Silica sand and marble were dried in a rotovapor for 48 hours. Then they were vacuum-coated with carbon (coating thickness between 3 and $10 \mathrm{~nm}$ ) in a vacuum pump (E.F. Fullam) at 50 mTorr; their surfaces were analyzed by SEM in a JEOL model JSM-5200 machine, in the secondary-electron mode.

\section{Acknowledgements}

Financial support by: the National Council of Science and Technology of Mexico (CONACyT, Grant \# 49899/2005); the Robert A. Welch Foundation (Grant \# B-1203); and the Hispanic Global Studies Initiative Fund of the University of North Texas, Denton. We appreciate the help of Mr. Francisco Garcia Flores in the sample irradiation performed at the Institute of Nuclear Sciences of the National Autonomous University of Mexico. Mr. Aldo Geovani Pérez Luna and Mr. David Uriel Pacheco Olalde, holders of undergraduate fellowships (CONACyT grants) have contributed to this project while working on their BS theses.

\section{References}

[1] Zollo, R.F. Cement and Concrete 1997, 19, 107.

[2] Khajuria, A.; Bohra, K.; Balaguru, P. in "Durability of Concrete", Malhotra, V.M., ed., ACl 2, Detroit, MI, 1991.

[3] Bunsell R.A.; Renard J. "Fundamentals of Fibre Reinforced Composite Materials", CRC Press, Boca Raton, FL 2005.

[4] Rebeiz, K.S.; Fowler, D.W.; Paul, D.R. J. Mater. Ed. 1991, 13, 441.

[5] Roy, D.M.; Sheetz, B.E.; Silsbee, M.R. J. Mater. Ed. 1993, 15, 1; Macphee, D.E.; Glasser, F.P. J. Mater. Ed. 1999, 15, 33.

[6] Gencel, O.; Brostow, W.; Ozel, C.; Filiz, M. Internat. J. Phys. Sci. 2010, 5, 216.

[7] Zheng, Z.; Feldman, D.; Progr. Polym. Sci. 1995, 20, 185.

[8] Martínez-Barrera, G.;. Vigueras-Santiago, E.;. Hernández-López, S.; Menchaca-Campos, C.; Brostow, W. Polym. Eng. \& Sci. 2005, 45, 1426.

[9] Beaudoin, J.J. "Handbook of Fiber-Reinforced Concrete: Principles, properties, developments and applications", Noyes Publications, Park Ridge, NJ, 1990. 
[10] Kurtz, S.; Balaguru, P.N. Cement and Concrete Res. 2000, 30, 183.

[11] Balaguru, P.N. ACl Materials J. 1994, 91, 280.

[12] Martinez-Barrera, G.; Martinez-Hernandez, A.L.; Velasco-Santos, C.; Brostow, W. e-Polymers 2009, no. 103.

[13] Menchaca, C.; Manoun, B.; Martínez-Barrera, G.; Castaño, V.M. J. Phys. \& Chem. Solids 2006, 67, 2111.

[14] Martinez-Barrera, G.; Espinosa-Pesqueira, M.E.; Brostow, W. e-Polymers 2007, no. 083.

[15] Martínez-Barrera, G.; Texcalpa-Villarruel, U.; Vigueras-Santiago, E.; Hernández-López, S.; Brostow, W. Polym. Compos. 2008, 29, 1210.

[16] Li, V.C.; Stang, H. Adv. Cement Based Mater. 1997, 6, 1.

[17] Brostow, W.; Hagg Lobland, H.E.; Narkis, M. J. Mater. Res. 2006, 21, 2422.

[18] Brostow, W.; Hagg Lobland, H.E. Polym. Eng. Sci. 2008, 48, 1982; Brostow, W.; Hagg Lobland, H.E. J. Mater. Sci. 2010, 45, 242.

[19] Berthelot, J.-M.; Ben, S.M.; Robert, J.L. J. Mater. Res. 1993, 8, 2344.

[20] Brocka, Z.; Schmachtenberg, E.; Ehrenstein, G.W. Proc. Ann. Tech. Conf. Soc. Plast. Engrs. (ANTEC-SPE) 2007, 67, 1690.

[21] Dole, M. "Radiation Chemistry of Macromolecules", Vol. 1-2, Academic Press, New York 1973.

[22] Timus, D.M.; Cincu, C.; Bradley, D.A.; Craciun, G.; Mateescu, E. Appl. Radn. \& Isotopes $2000,53,937$.

[23] Menchaca-Campos, C.;. Martínez-Barrera, G.; Alvarez-Castillo, A.; Lara, V.H.; Lopez-Valdivia, H.; Carrasco-Abrego H.; Ch. 6 in "Gamma radiation effects on polymeric materials and their applications", eds. Barrera-Díaz, C.; MartínezBarrera, G.; Research Signpost, Kerala, India 2009.

[24] Thanki, P.N.; Ramesh, C.; Singh, R.P. Polymer 2001, 42, 535.

[25] Menchaca, C.; Alvarez-Castillo, A.; Martínez-Barrera, G.; López-Valdivia, H.; Carrasco, H.; Castaño, V.M. Internat. J. Mater. \& Prod. Tech. 2003, $19,521$.

[26] Menchaca-Campos, C.; Martínez-Barrera, G.; Resendiz, M.C.; Lara, V.H.; Brostow, W. J. Mater. Res. 2008, 23, 1276.

[27] Menchaca, C.; Demesa, G.; Santiaguillo, A.; Martínez-Barrera, G.; López Valdivia, H.; Carrasco, H., submitted to Rad. Phys. \& Chem., 2009.

[28] Martínez-Barrera, G.; Giraldo, L.F.; López, B.L.; Brostow, W. Polym. Compos. 2008, 29, 1244.

[29] Brostow, W.; Deshpande, S.; Fan, K.; Mahendrakar, S.; Pietkiewicz, D.; Wisner, S.R. Polym. Eng. Sci. 2009, 49, 1035.

[30] Brostow, W.; Deshpande, S.; Pietkiewicz, D.; Wisner, S.R. e-Polymers 2009, no. 109.

[31] Martínez-Barrera, G.; Menchaca-Campos, C.; Hernández-López, S.; ViguerasSantiago, E.; Brostow, W. J. Mater. Res. 2006, 21, 484.

[32] Menchaca, C.; Nava, J.C.; Valdéz, S.; Sarmiento-Martínez, O.; Uruchurtu, J. submitted to J. Mat. Sci. \& Eng., 2009.

[33] Patel, M.; Morrell, P.R.; Murphy, J.J.; Skinner, A.; Maxwell, R.S. Polymer Degrad. \& Stab. 2006, 91, 406.

[34] Kopczynska, A.; Ehrenstein, G.W. J. Mater. Ed. 2007, 29, 325. 